\title{
One plus one is greater than two: mixing litter types accelerates decomposition of low-quality alpine dwarf shrub litter
}

\author{
Michael Steinwandter (D) B Birgit C. Schlick-Steiner • \\ Florian M. Steiner • Julia Seeber
}

Received: 24 July 2018 / Accepted: 13 February 2019/Published online: 21 March 2019

(C) The Author(s) 2019

\begin{abstract}
Aims Litter decomposition patterns, non-additive effects, and spectral data of abundant alpine leaf litters were assessed in litterbag experiments containing single species and mixtures. We tested if low-quality shrub litter decomposes faster in mixtures with high-quality litter and if predictions on decomposed litter using spectral data are feasible.

Methods Chemical and physical traits and near-infrared reflectance (NIR) spectra of six alpine freshly fallen litter types were measured. A litterbag experiment (0.1 mm mesh size) with single and 2- and 3-species mixtures was conducted with three species from three functional groups (shrub, grass, forb). Decomposition rates, litter mass loss, non-additive effects, and NIR spectra were recorded after 6, 12, and 24 months.

Results The six freshly fallen litter types differed significantly in leaf litter traits and NIR spectra. Decomposition rates steadily slowed during the 24 months, with shrub
\end{abstract}

Responsible Editor: Alfonso Escudero.

Electronic supplementary material The online version of this article (https://doi.org/10.1007/s11104-019-03991-5) contains supplementary material, which is available to authorized users.

M. Steinwandter $(\bowtie) \cdot J$. Seeber

Institute for Alpine Environment, Eurac Research, Viale Druso 1, 39100 Bozen/Bolzano, Italy

e-mail: Michael.Steinwandter@eurac.edu

M. Steinwandter - B. C. Schlick-Steiner - F. M. Steiner •

J. Seeber

Department of Ecology, University of Innsbruck, Technikerstrasse

25, 6020 Innsbruck, Austria litter having the lowest on all sampling dates. In litter mixtures, shrub and grass litter showed higher decomposition rates after 12 and 24 months compared with the single-species treatments.

Discussion The accelerated decomposition in litter mixtures indicates stimulating interactions between low- and high-quality litter types, most probably mediated by their associated microbiomes. By using NIR spectra, we successfully predicted all initial litter traits, but only total carbon content along the entire decomposition period.

Keywords Litterbags · Non-additive effects · Vaccinium $\cdot$ Litter mass loss $\cdot$ Partial least squares regression $\cdot$ Land-use change
Abbreviations
SHRUB_Vv low-quality litter of Vaccinium vitis- idaea L., an evergreen dwarf shrub
GRASS_Dg high-quality litter of Dactylis glomerata L., a perennial grass
FORB_Gs high-quality litter of Geranium sylvaticum L., a forb
LML litter mass loss
NIRS near-infrared reflectance spectroscopy
PLS Partial Least Squares regression

\section{Introduction}

The decomposition of plant litter material on the soil surface is essential for terrestrial ecosystems by means of influencing vital ecosystem services such as nutrient cycling, carbon sequestration, and above- and below- 
ground biodiversity (Berg and McClaugherty 2014). The litter decomposition rates strongly depend on (i) temperature and (soil) moisture, (ii) the chemical and physical traits as well as the nutrient availability of the plant material (e.g. litter quality), (iii) site-specific local factors (e.g. microclimate), and (iv) the composition of the soil decomposer community (Coûteaux et al. 1995; Berg and McClaugherty 2014; Bradford et al. 2016).

In most natural habitats, leaves and stems from an array of plant species belonging to different functional groups (e.g. shrubs, grasses, and forbs) contribute to building up the litter layer. During decomposition, these litter types - and their associated microbiomes - interact, and it has increasingly been recognized that patterns are often not predictable from single-species dynamics (Gartner and Cardon 2004; Hättenschwiler et al. 2005). Litter types influence each other's decomposition rates by changing the chemical environment and by physically altering the litter surface, resulting in non-additive patterns (Gartner and Cardon 2004). Cuchietti et al. (2014), for example, found that the decomposition of slow-decomposing low-quality leaf litter can be accelerated by mixing with fastdecomposing high-quality litter.

In alpine and arctic ecosystems, slower decomposition rates compared with lower and warmer habitats were observed (Cornelissen et al. 2007). The lower temperatures along with a more shrubby and recalcitrant plant material, which contains high amounts of secondary plant products such as phenols and lignin, were found to be the main factors leading to slower decomposition rates (Aerts and Chapin 1999; Xu et al. 2010; Duan et al. 2013; Bradford et al. 2016). Possible consequences are litter accumulation and changes in soil properties (Seeber and Seeber 2005), affecting the above- and below-ground plant (Pruchniewicz 2017) and invertebrate species composition (Steinwandter et al. 2017). Increased temperatures due to global warming, which are predicted to be more severe in high-latitude and high-elevation regions (IPCC 2013), could on the one hand enhance decomposition in alpine ecosystems, but on the other hand limit it through reduced (soil) moisture (Aerts 2006) and through lowquality shrub litter replacing high-quality litter species (Cornelissen et al. 2007).

Some studies on litter decomposition in alpine grassland exist (e.g. Wang et al. 2010; Saccone et al. 2013; Liu et al. 2016), but little is known on interactions of alpine leaf litter mixtures (e.g. Xu et al. 2010; Duan et al.
2013; Chen et al. 2015), especially from the Alps. Beneficial interactions (i.e. positive non-additive effects) that accelerate litter decomposition and counteract litter accumulation might also apply to high-elevation ecosystems such as semi-natural grasslands in the Alps, but have not been investigated yet. Therefore, we conducted a litterbag experiment over the course of 24 months with alpine leaf litter from three functional groups (i.e. grass, forb, and dwarf shrub as singlespecies treatments and mixtures). Contrary to most alpine litterbag studies, we used fine-meshed litterbags that excluded soil meso- and macro-decomposers that might feed on the litter material, thus investigating the pure decomposition induced by microbial (Knapp et al. 2011) and physical processes. We assessed leaf litter traits and additionally measured the spectral composition by using near-infrared reflectance spectroscopy (NIRS). To date, only few litter decomposition studies included NIRS (e.g. Joffre et al. 1992; Parsons et al. 2011), although it has been proven an effective method to measure plant and litter chemical traits as well as soil material (Chodak 2008; Agelet and Hurburgh 2010).

In this study, we tested the hypothesis that along 24 months of decomposition, low-quality dwarf shrub litter degrades faster if mixed with high-quality litter. Further, we tested if NIRS can be a suitable tool for predicting litter traits of decomposed leaf litter material. Knowing the litter traits and spectral composition of key litter types from Alpine grassland will considerably enhance our understanding of alpine decomposition patterns. Further, it will help us to better anticipate the effects of ongoing Alpine land-use change (i.e. abandonment) and global warming (Brigham et al. 2018) on alpine litter decomposition as they might negatively affect soil processes, plant species compositions (i.e. due to shrub encroachment), the decomposer community (i.e. change in litter quality), and subsequently a variety of ecosystem services.

\section{Material and methods}

Study site

Figure 1 summarizes design and working steps of this study. About $500 \mathrm{~g}$ freshly fallen leaf litter of six common and abundant alpine plants as representatives of the functional groups grass, forb, and dwarf shrub were collected at the Alpine Long-Term Ecological 
Research (LTER) area "Kaserstattalm" (Central Alps, Tyrol, Austria; site code LTER_EU_AT_015; 47.1250 $\mathrm{N}, 11.2900^{\circ} \mathrm{E}$ ) in autumn 2012 . The sampling area, managed and abandoned pastureland, ranged from 1950 to $2050 \mathrm{~m}$ above sea level (a.s.l.) in elevation (Steinwandter et al. 2017). The mean annual temperature (MAT) and precipitation (MAP) at $1900 \mathrm{~m}$ a.s.l. are $3.0^{\circ} \mathrm{C}$ and $1097 \mathrm{~mm}$, respectively (Ingrisch et al. 2017). During the experiment, climatic conditions were recorded (Fig. A1). The first winter (i.e. 2012/2013) was colder than the second winter (monthly averages of surface temperatures in December with $-10.2{ }^{\circ} \mathrm{C}$ and $-8.7^{\circ} \mathrm{C}$, respectively). In both winters, relatively low snow covers (i.e. about $30 \mathrm{~cm}$ ) were observed, with more snow occurring in late 2014 (ca. $60 \mathrm{~cm}$, pers. observation). The summer 2013 was relatively dry, while the summer 2014 had more and evenly distributed precipitation (Fig. A1).

\section{Litter material}

The litter types were the perennial grasses (i) Dactylis glomerata L., Poaceae; (ii) Nardus stricta L., Poaceae; (iii) Luzula lutea (All.) DC., Juncaceae; the forb (iv) Geranium sylvaticum L., Geraniaceae; and the evergreen dwarf shrubs (v) Vaccinium vitis-idaea L.,
Ericaceae; and (vi) Calluna vulgaris L., Ericaceae. This litter material was cleaned thoroughly from dirt and green plant parts (e.g. mosses) before air-drying (Fig. A2).

Ten chemical and physical litter traits of initial litter with four replicates each were analysed following the protocols of VDLUF method book volume III (2018). These were (i) crude ash by drying material at $105{ }^{\circ} \mathrm{C}$ and ashing it at $550{ }^{\circ} \mathrm{C}$ (see chapter 8.1 in the VDLUF method book), (ii) crude protein via the Dumas combustion method (ch. 4.1.2), (iii) crude fibre by processing the material with boiling hydrochloric acid and potash lye, washing, drying, and ashing it at $500{ }^{\circ} \mathrm{C}$ (ch. 6.1.1), (iv) acid detergent fibre (ADF) by boiling the material for $1 \mathrm{~h}$ in acid detergents solution, filtering and washing it (ch. 6.5.2), (v) acid detergent lignin (ADL) by processing the filtered ADF material with $72 \%$ sulphuric acid for $3 \mathrm{~h}$, washing and drying it (ch. 6.5.3), (vi) calcium (Ca), phosphorus $(\mathrm{P})$, magnesium $(\mathrm{Mg})$, potassium $(\mathrm{K})$, and sodium $(\mathrm{Na})$ by solving ashed material in hydrochloric acid, washing and drying it before determining it via inductively coupled plasma optical emission spectrometry (ICP-OES, ch. 10). Additionally, total carbon (C) and total nitrogen (N) content were analysed for all replicates and sampling dates using an organic elemental analyser (FlashEA
Field experiments

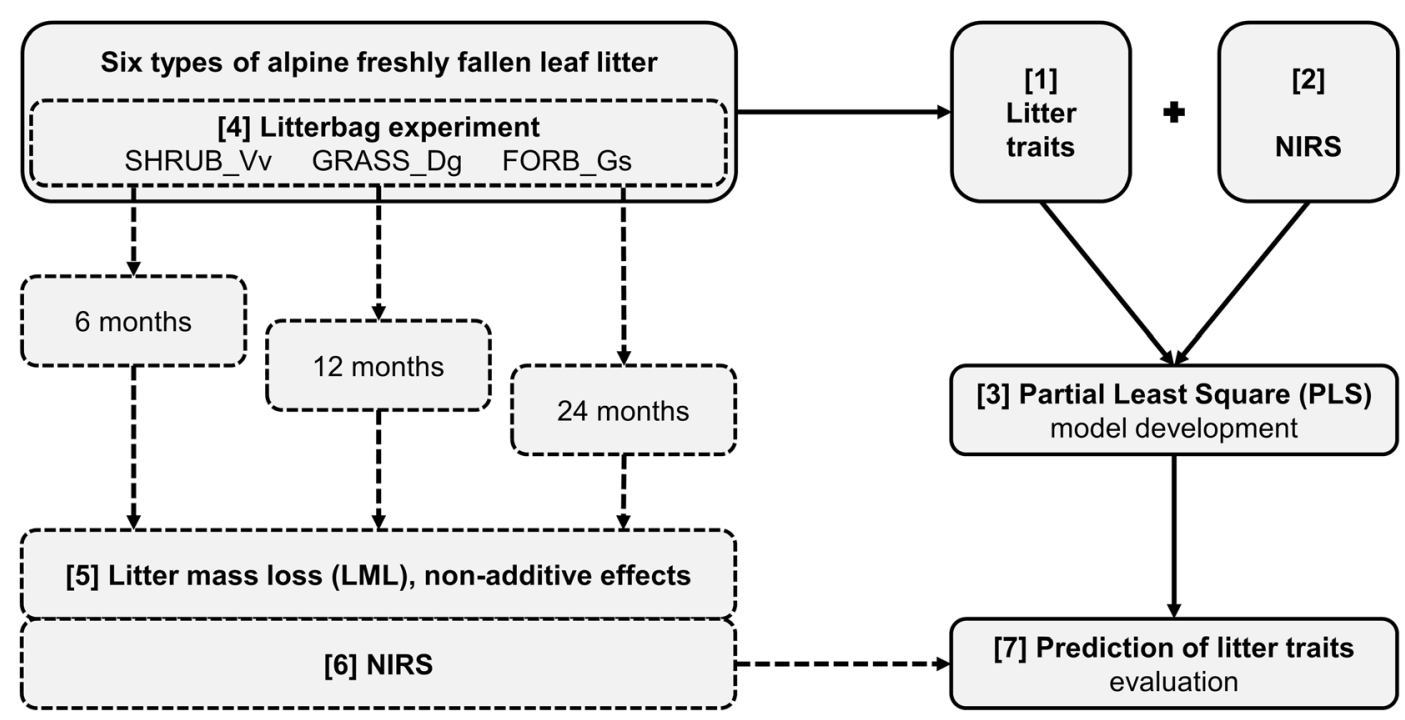

Fig. 1 Scheme of the study design and working steps. Litter traits [1] and NIR spectra [2] data of freshly fallen alpine leaf litter types were combined in PLS models [3] to develop prediction models for the decomposed litter material. In the leaf litterbag experiment, LML, decomposition rates and non-additive effects [5] as well as NIR spectra [6] were measured. The NIR spectra of decomposed litter were used to test the prediction model based on the freshly fallen litter [7] 
1112, Thermo Fisher Scientific, Waltham, Massachusetts). Based on these results (Fig. 2, Table 1) and due to their high abundance at the study site, the following three litter types were chosen for the litterbag experiment: $V$. vitis-idaea (further on referred to as SHRUB_Vv), D. glomerata (GRASS_Dg), and G. sylvaticum (FORB_Gs). Abbreviations are used to facilitate identification of this three litter types but do not represent the entire functional groups.

\section{Leaf litterbags}

Each of the following treatments was replicated 15 times: (i) single-species treatments of SHRUB_Vv, GRASS_Dg, and FORB_Gs; (ii) 2-species mixtures of SHRUB_Vv + GRASS_Dg, SHRUB_Vv + FORB_Gs, and GRASS_Dg + FORB_Gs; and (iii) a 3-species mixture SHRUB_Vv+GRASS_Dg +FORB_Gs. Each polyamide litterbag (size of $\overline{15} \times 15 \mathrm{~cm}$, mesh size of $0.1 \mathrm{~mm})$ was filled with $10.00 \mathrm{~g}( \pm 0.01)$ air-dried mass of the corresponding plant material; $10.00 \mathrm{~g}, 5.00 \mathrm{~g}$ and $3.33 \mathrm{~g}$ in the single-species treatments, 2 -species mixtures, and 3-species mixtures, respectively. In the mixtures, a $1 \mathrm{~mm}$ mesh size fly net separated the litter types while at the same time ensuring direct contact. The fine mesh size excluded soil meso- and macroinvertebrates and hindered roots growing into the litter material.

At the incubation site (area of approx. $3 \times 10 \mathrm{~m}$ of an abandoned pasture at $2000 \mathrm{~m}$ ), the vegetation was cut to $1 \mathrm{~cm}$ height to ensure maximum contact of the litterbags with the surface. The pasture was abandoned since 1983, the vegetation was described as SeslerioCaricetum with scattered dwarf shrubs (Ingrisch et al. 2017; Steinwandter et al. 2017). The litterbags were placed randomly on the ground and secured with a coarse metal grid. The cut vegetation was scattered onto the litterbags to simulate vegetation presence and to prevent desiccation. In total, 105 litterbags were incubated in October 2012.

After 6, 12, and 24 months, five replicates of each treatment were sampled, cleaned, sorted, and separated into the single-litter types, air-dried, and finally weighed. The litter mass loss (LML) was depicted as the percentage of loss from the initial air-dried mass. The litter decomposition rate $k$ was calculated using the
Fig. 2 Biplot of an unconstrained Principal Component Analysis (PCA) of chemical traits of six alpine litter types. This plot explains $76.34 \%$ of the variability of the litter traits. The shaded areas represent 2D-normal-based ellipses covering $95 \%$ of data distribution estimated from the variance-covariance matrix of their $\mathrm{X}$ and $\mathrm{Y}$ coordinates. Legend: triangles represent grass, circles forb, and rhombi the dwarf shrub leaf litter. The arrows represent the litter traits.

Eigenvalues: axis $1=0.4825$, axis $2=0.2309$

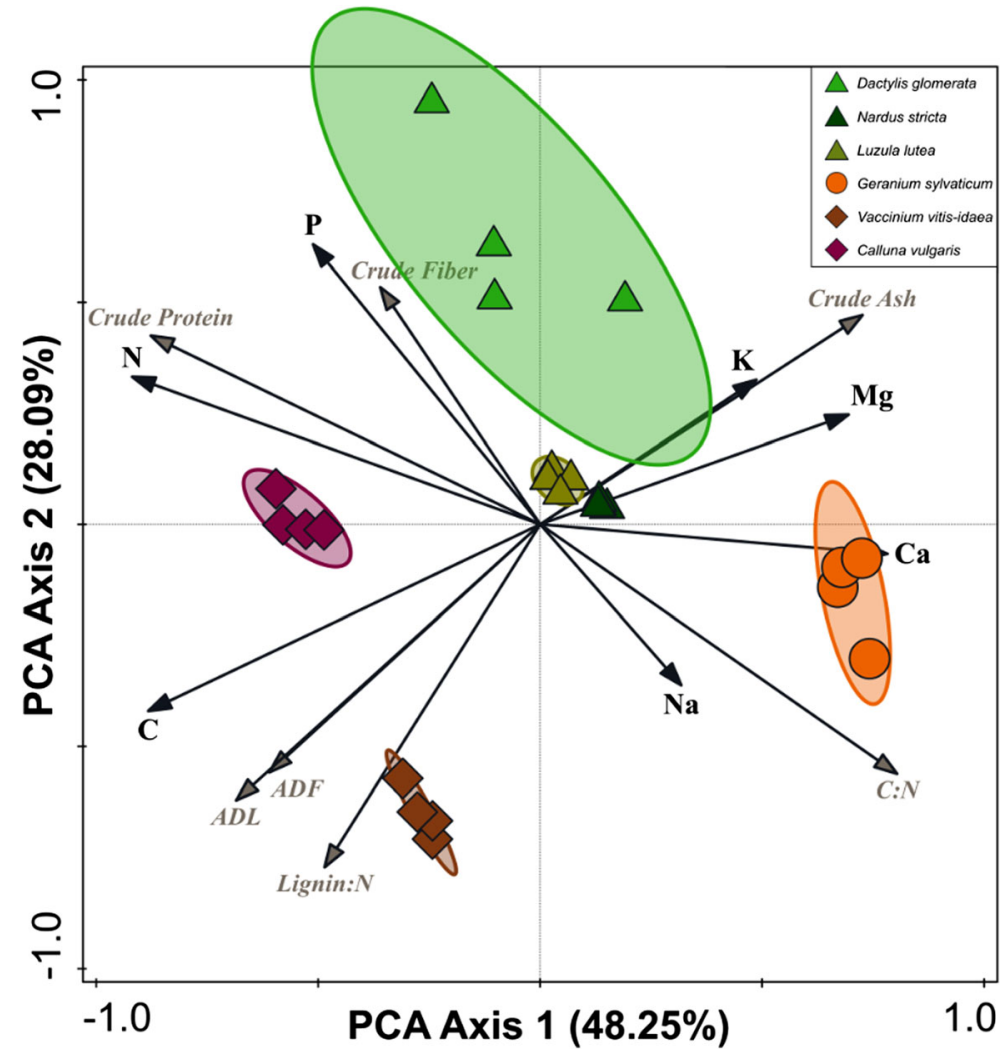




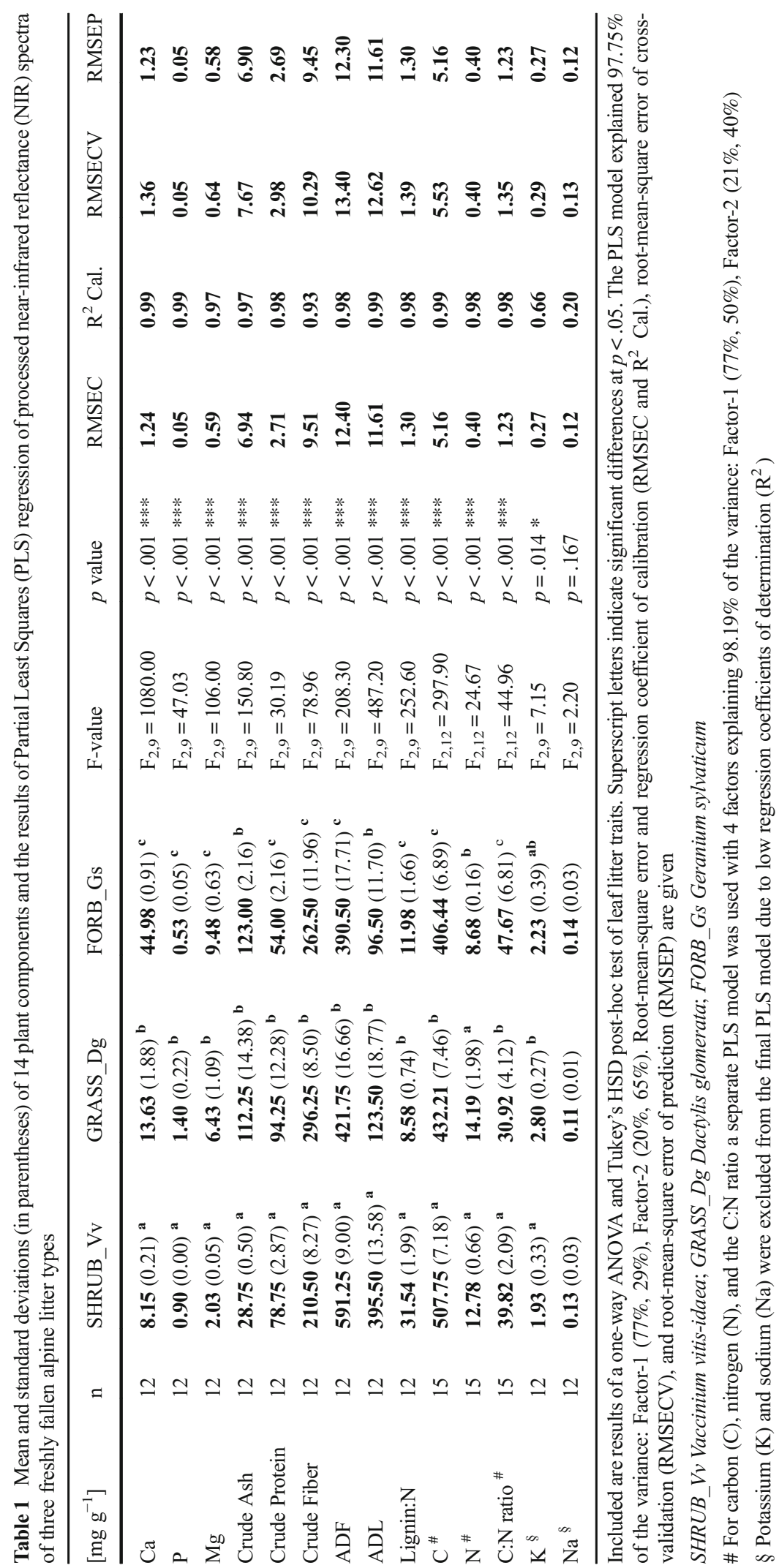


equation $\ln \left(M_{t} / M_{0}\right)=-k t$, in which $M_{0}$ is the initial litter biomass and $M_{t}$ the biomass at a certain time point $t$ (Olson 1963). In calculating decomposition rates between sampling dates, $M_{0}$ was the litter mass at the earlier date, $t$ the time between the dates (i.e. 0.5 and 1.0 years; for this calculation, months were converted to years), and $M_{t}$ the litter mass remaining after $t$.

Near-infrared reflectance spectra

Near-infrared reflectance spectroscopy (NIRS) represents a fast, low-cost, and non-destructive technology of increasing popularity in ecology (Foley et al. 1998), agriculture (Martinez et al. 2010), biodiversity studies (Kinzner et al. 2015), pharmacology (Reich 2005), and more recently also in soil studies (Chodak 2008; Zangerlé et al. 2014). It analyses elements and compounds with certain chemical bonds that reflect the radiation in different ways.

Litter material was stored in an oven for $48 \mathrm{~h}$ at $60^{\circ} \mathrm{C}$ before being milled to powder in a ball mill (Retsch, Haan, Germany) and sieved through a $1 \mathrm{~mm}$ screen. Each sample consisted of one to two grams of ovendried litter material which was transferred to a small round plastic container and flattened gently with a spatula to obtain a smooth measuring surface (approx. $1 \mathrm{~cm}^{2}$ ). Constant room conditions (i.e. temperature, humidity, and light) and the distance from samples to the NIRS light emitting probe (diameter of $3 \mathrm{~mm}$ ) were identical across all NIRS measurements. Each sample was scanned five times according to a crosswise scheme (i.e. centre and cardinal points) with a portable VIS/NIR spectrophotometer (LabSpec 5000, ASD, Boulder, Colorado); each spectrum was achieved by averaging 50 measurements. Each replicate was measured five times, resulting in 25 spectra per replicate, 100 spectra per initial, and 125 spectra per decomposed litter type. We measured the reflectance ranging from 300 to $2500 \mathrm{~nm}$ and $1 \mathrm{~nm}$ resolution; regular calibrations were made using a white Spectralon® plate with $2.2 \mathrm{~mm}$ distance to the probe (Kinzner et al. 2015). The reflectance spectra $(R)$ were converted to absorbance spectra (A) using the eq. $A=\log (1 / R)$.

\section{Statistical analyses}

Differences in plant components and LML were analysed using Analyses of Variance (ANOVA, at significance level $p<.05$ and Tukey's HSD post-hoc tests) with the factors sampling date * litter type. Linear mixed-effects models with random factor time were calculated for LML across the entire decomposition period using the package LME4 (version 1.1-19, Bates et al. 2014) in the open-source statistical programming language $\mathrm{R}$ (version 3.5.2, R Core Team 2018) in RStudio (version 1.1.463, RStudio Team 2016). Principal Component Analyses (PCA) of plant components were calculated using Canoco 5.11 (Ter Braak and Šmilauer 2018).

Non-additive effects on LML are defined as the deviance from the sum of the purely LML observed for each individual plant species in litter mixtures (Hättenschwiler et al. 2005). They were calculated as the difference of the individual observed LML (of the single litter types in the mixtures) minus the expected mean LML (of the corresponding single-species treatments). If the difference is a positive value, the effects are called synergistic; when negative, antagonistic.

All NIR spectra data transformations and calculations were performed with the multivariate data analysis software The Unscrambler X 10.5 (CAMO Software, Oslo, Norway). All spectra were pre-processed: First, the wavelength range was reduced from 500 to $2300 \mathrm{~nm}$ (i.e. 1800 data points) due to high distortion at the endpoints. Then, the spectra were smoothed using Savitzky-Golay derivates (polynomial order 2, 11 smoothing points) and Extended Multiplicative Scatter Correction (EMSC) (Agelet and Hurburgh 2010; CAMO Software 2017). Finally, the spectra were reduced by factor 5 corresponding to the average spectra of the five crosswise measurements per plastic container. Thus, we obtained 20 spectra for each initial (i.e. 0 month) and 25 spectra for each decomposed litter type. The covariance of litter traits and NIR spectra data was maximised in Partial Least Squares (PLS) regression models with the Wide Kernel PLS algorithm; the litter traits data were centred and standardised. One outlier was removed according the Hoteling $\mathrm{T}^{2}$ outlier detection (Agelet and Hurburgh 2010; CAMO Software 2017). We finally proceeded with the best PLS model using just the three main litter types data and 12 out of 14 plant components (i.e. excluding $\mathrm{K}$ and $\mathrm{Na}$ ), resulting in $97.75 \%$ average explanation of variance using four factors (for details see Table 1). Additionally, we validated the PLS model with blind samples gaining satisfying results (i.e. $\mathrm{R}^{2}$ greater than 0.90 ). 


\section{Results}

Plant components and near-infrared reflectance spectra

The six freshly fallen alpine litter types significantly differed in their litter traits (Fig. 2; Table 1 and A1) and NIR spectra (Fig. A3 and A4). In FORB_Gs Ca concentration was very high with almost $45 \mathrm{mg} \mathrm{g}^{-1}$, while all grasses and dwarf shrubs remained below $14 \mathrm{mg} \mathrm{g}^{-1}$; for $\mathrm{Mg}$ we found a similar but less pronounced result $\left(9.48 \mathrm{mg} \mathrm{g}^{-1}\right.$ vs. $2.08 \mathrm{mg} \mathrm{g}^{-1}$ in FORB_Gs and SHRUB_Vv, respectively). However, FORB_Gs had the lowest P, total C and $\mathrm{N}$ content, the latter resulting in the widest and most variable mean $\mathrm{C}: \mathrm{N}$ ratio of $47.67 \pm 6.81$. The two dwarf shrub species showed the highest total $\mathrm{C}$ content exceeding $500 \mathrm{mg} \mathrm{g}^{-1}$. The three litter types used in the litterbag experiment differed significantly in all measured plant components except the Na content (Table 1).

Along the decomposition process, total $\mathrm{C}$ and $\mathrm{N}$ content changed differently for each litter and mixture type (Table A3). The total C content of the SHRUB_Vv single-species treatments increased only slightly, whereas the total $\mathrm{N}$ content significantly increased stepwise at each sampling date. Therefore, also the C:N ratio significantly decreased from $39.82 \pm 2.09$ to $25.21 \pm 1.17$. The total C and N content from the SHRUB_Vv material within litter mixtures, in most cases, were similar to the single-species treatments. However, the SHRUB_Vv + F (i.e. SHRUB_Vv litter in the SHRUB_Vv + FORB_Gs mixture) and the 3-species treatments (SHRUB_Vv + GF) had the significantly lowest total $\mathrm{C}$ content after 6 and 12 months, and therefore also a significantly narrower $\mathrm{C}: \mathrm{N}$ ratio compared with the single-species treatments. In contrast, the $\mathrm{C}$ and $\mathrm{N}$ content of GRASS_Dg and FORB_Gs litter increased significantly after six months and levelled off at this concentration for the rest of the experiments. As a consequence, the C:N ratio of GRASS_Dg and FORB_Gs dropped from 30.92 \pm 4.12 and $47.67 \pm 6.81$, respectively, to values around 20 .

A clear separation of four out of six alpine litter types can be seen; the grasses $N$. stricta and L. lutea showed low correspondence to the plant components in the PCA plot (Fig. 2). The intra-specific variation was highest in D. glomerata (i.e. GRASS_Dg) showing the largest grouping area (green ellipse). The result of the PCA plot supports the selection of the abundant species $V$. vitis- idaea, D. glomerata, and G. sylvaticum (i.e. SHRUB_Vv, GRASS_Dg, and FORB_Gs, respectively) for the litterbag experiment, as they are located the farthest away in the plot (Fig. 2).

In addition, SHRUB_Vv, GRASS_Dg, and FORB_Gs differed significantly regarding their NIR spectra during the 24 months of decomposition (Fig. A5). The four sampling dates followed a similar pattern for all three litter types: considering their NIR spectra, the initial freshly fallen litter was always the most different one located on the opposite side from the decomposed litter in the PCA plots (Fig. A5). The NIR spectra of the latter were found to cluster together but were still clearly separated.

Mean litter mass loss and decomposition rates

The decomposition rates differed significantly between treatments within each sampling date and along the entire decomposition period, and slowed down with time (Tables 2 and 3; Fig. A6). SHRUB_Vv litter decomposed significantly slower compared with the other two litter types with a mean LML of only $25.4 \% \pm 1.7$ after 24 months. Further, it had the significantly lowest mean decomposition rates at each sampling point; the initial rate after six months $(k=0.25 \pm 0.04)$ was even less than half of that of FORB_Gs after 12 months. FORB_Gs showed the highest (i.e. fastest) mean litter decomposition rate with $64.6 \% \pm 2.9 \mathrm{LML}$ after 24 months, followed by GRASS_Dg (LML of $47.0 \% \pm 1.6$, Table 2 and Fig. A6).

In the litterbags with 2- and 3-species mixtures, we observed a deviation of the collective LML from the average LML of the single-species decomposition rates. Accelerated decomposition rates were found especially for the 12 and 24 months treatments as observed by a positive deviation from the mean calculated from the single-species treatments (Table 3). For example, after 12 months a mean of $19.2 \%$ of the SHRUB_Vv and $35.4 \%$ of the GRASS_Dg single-species litter were decomposed. In the SHRUB_Vv+GRASS_Dg litter mixture, $33.2 \%$ were decomposed after 12 months, i.e. $5.9 \%$ more than the average of both single-species treatments (i.e. 27.3\%). Again, decomposition rates gradually slowed down with time, except for the mixture GRASS_Dg + FORB_Gs, which had the same mean $k$-values for the 6 and 12 months treatments (Table 3). 
Table 2 Estimated deviants from intercepts (i.e. single-species treatments) for mean litter decomposition rates $k$ and mean litter mass loss (LML) of single-species treatments and 2- and 3-species mixtures of three alpine leaf litter types after three time points along the decomposition process

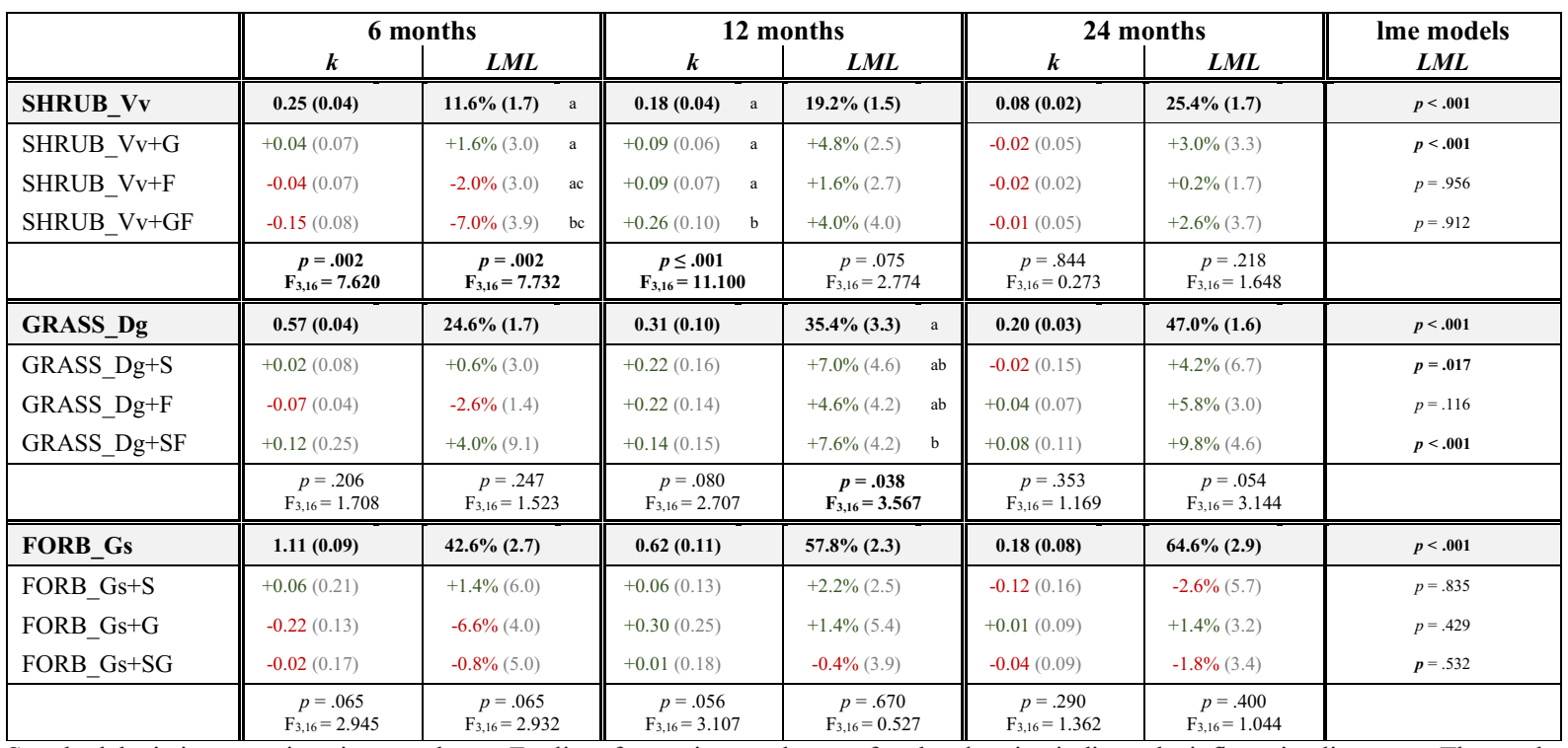

Standard deviations are given in parentheses. For litter from mixtures, letters after the plus sign indicate the influencing litter type. The results of a two-way ANOVA (with Tukey's HSD post-hoc test) within sampling dates are given with $k *$ influence and LML $*$ influence, respectively. Superscript letters indicate differences between the groups at $p<.05$ level. For litter from the mixtures, positive (green) and negative (red) deviations from the expected values (i.e. the mean of the corresponding single-species treatments) are presented. The results of linear mixed-effect models over the entire decomposition period are given (lme). $n=5$.

SHRUB_Vv Vaccinium vitis-idaea; GRASS_Dg Dactylis glomerata; FORB_Gs Geranium sylvaticum

\section{Non-additive effects}

The individual decomposition rates of litter in the 2- and 3 -species mixtures generally showed highly variable patterns within and among treatments (Table 2). For example, after six months of decomposition no clear pattern could be found in the 2- and 3-species mixtures, with both lower (e.g. significant for SHRUB_Vv + GF) as well as higher decomposition rates compared with the single-species treatments. At this point, the litter types seemed not to profit from one another, especially GRASS_Dg and FORB_Gs even seemed to hamper each other. However, after 12 months of decomposition 12 and 15 out of the 18 mixtures showed accelerated (but not always significantly different) mean decomposition rates and LML, respectively, compared with their corresponding single-species treatments (Table 2). The SHRUB_Vv litter decomposed slightly faster in the 2and 3-species mixtures, resulting in mean synergistic effects for LML of up to $+3.5 \%$ and $+1.9 \%$, respectively, which was highly significant for SHRUB_Vv+G considering the entire decomposition period $(p<.001)$. Additionally, the mean decomposition rate $k$ indicated slightly higher values for each SHRUB_Vv mixture material after 12 months; the effect was significant in the 3 -species mixture. After 24 months, a similarly positive but less pronounced effect of the decomposition rate was found for both the SHRUB_Vv and the GRASS_Dg mixture but not for FORB_Gs (Table 2).

The non-additive effects of SHRUB_Vv litter in the 3species mixture results in the steepest positive slope of the linear trend line (Fig. 3), implying the highest acceleration of decomposition when more species were present. We found a similar picture for GRASS_Dg with a highly significant positive effects for GRASS_Dg + SF but not for FORB_Gs, in that decomposition was only slightly accelerated when combined with GRASS_Dg (Fig. A7).

Partial least squares predictions

Including all six alpine litter types resulted in lower calibration, cross-validation, and prediction scores compared with including only the three main species which were used for the litterbag experiment (i.e. SHRUB_Vv, FORB_Gs, and GRASS_Dg).

Using the PLS models to predict the values for decomposed litter worked well only for some litter types and plant components (Table A2). For example, 
Table 3 Mean litter decomposition rates $k$ and litter mass loss (LML) of single-species litter and 2- and 3-species mixtures of three alpine leaf litter types at three time points along the decomposition process

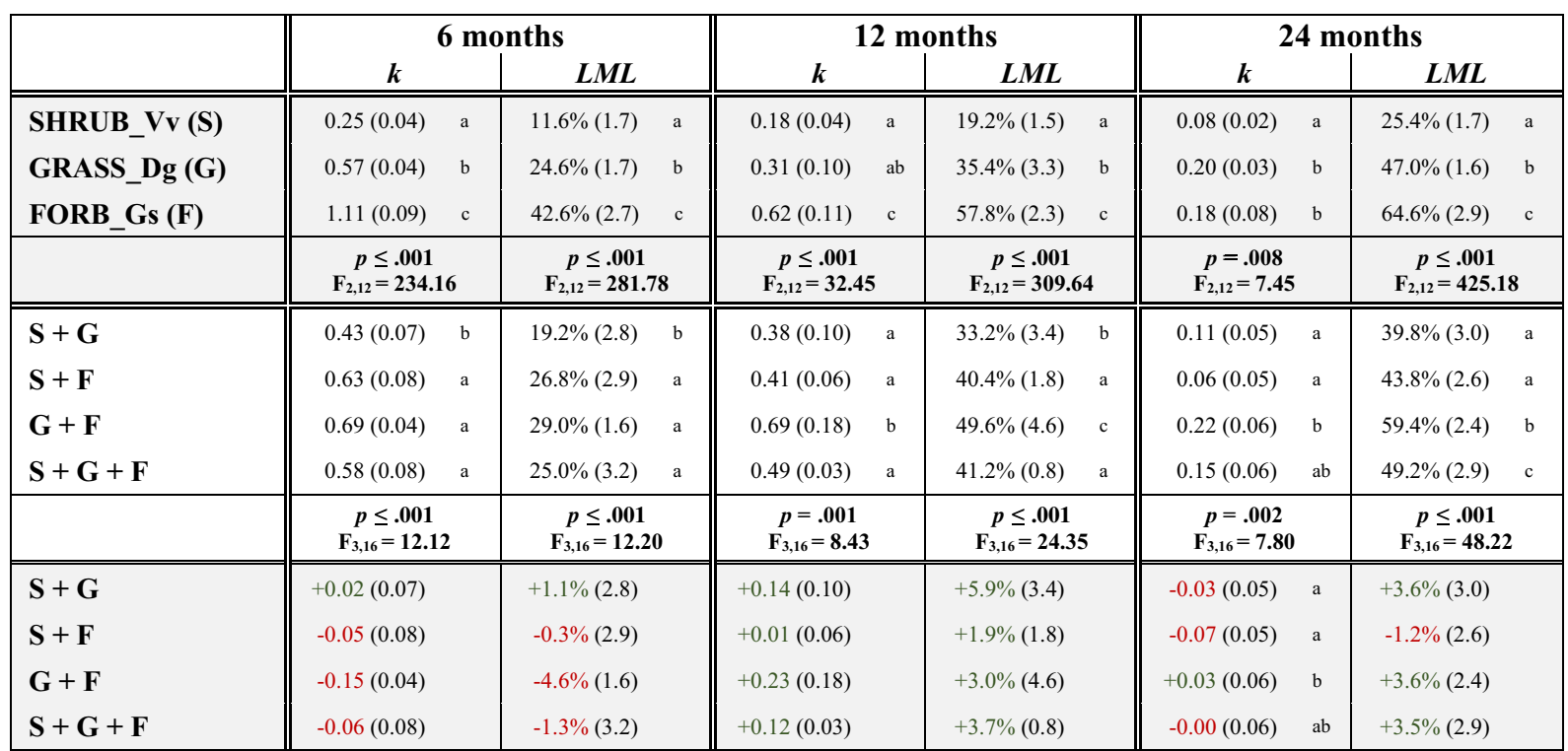

Standard deviations are given in parentheses. The results of a two-way ANOVA (with Tukey's HSD post-hoc test) within sampling dates are given with $k *$ influence and $L M L *$ influence, respectively. For the mixtures, positive (green) and negative (red) deviations from the expected values (i.e. the mean of the corresponding single-species treatments) are presented at the bottom. Superscript letters indicate differences between the groups at $p<.05$ level. $\mathrm{n}=5$.

SHRUB_Vv Vaccinium vitis-idaea; GRASS_Dg Dactylis glomerata; FORB_Gs Geranium sylvaticum

the total $\mathrm{C}$ content values of the 12 months old SHRUB_Vv and GRASS_Dg single-species litter were predicted very well (average deviation $+0.3 \%$ and $+2.7 \%$, respectively), while we obtained high deviations for the FORB_Gs single-species treatment $(+12.7 \%)$ that exceeded the $95 \%$ confidence limit. On the other hand, total $\mathrm{N}$ content and thus also C:N ratio predictions were both highly underestimated for the former (up to $-25.8 \%$ for SHRUB_Vv+G) and highly overestimated for the latter (up to $+91.1 \%$, FORB_Gs). We obtained a similar outcome for the six and 24 month old litter predictions, the total $\mathrm{C}$ content showing proper values, while those of total $\mathrm{N}$ content and $\mathrm{C}: \mathrm{N}$ ratio were again predicted incorrectly (Table A2).

\section{Discussion}

To our knowledge, we are the first to combine both litter traits and spectral data of six common alpine plant species; three of them even over the course of 24 months of decomposition. Generally, more litter decomposition studies - ideally multiple-method studies like this one - are needed to better understand decomposition patterns of multi-species litter, not only in alpine ecosystems. The investigated Alpine decomposition patterns were in line with our expectations based on previous studies (e.g. Rief et al. 2012) and the literature as in this study recalcitrant SHRUB_Vv litter showed the slowest and both high-quality GRASS_Dg and FORB_Gs litter a significantly faster decomposition (Montané et al. 2010; Duan et al. 2013; Berg 2014). Further, we found both synergistic and antagonistic nonadditive effects on LML in litter mixtures, similar to the few-species mixtures in the study of Duan et al. (2013). Analyses of the NIR spectra of litter material successfully separated litter types, functional groups as well as the decomposition stages. However, reliable predictions were possible only for the total $\mathrm{C}$ content due to methodological constraints.

Near-infrared reflectance spectra and partial least squares predictions

The successful prediction of soil properties by using NIRS such as total $\mathrm{C}$ and $\mathrm{N}$ content, soil moisture, and 
others, has been shown by Chang et al. (2001), resulting in correlations of measured and predicted values that exceeded $R^{2}>0.80$. In this study, we successfully validated our PLS model with the initial litter material. Further, we were able to validate PLS predictions for total $\mathrm{C}$ and total $\mathrm{N}$ content, and thus also for the $\mathrm{C}: \mathrm{N}$ ratio of the decomposed SHRUB_Vv, GRASS_Dg, and FORB_Gs litters (Table A2). These parameters were measured for all the litter material along the entire decomposition experiment. However, when attempting to predict the other litter traits of the decomposed from the freshly fallen litter material, we encountered difficulties in terms of extremely high deviations of the predicted values.

Generally, litter traits considerably change during the decomposition process (Cornelissen and Thompson 1997; Berg 2014). Therefore, the PLS model which was built on the initial litter material (i.e. 0 months) was not able to predict the litter traits of the decomposed litter (6 to 24 months). In other words, PLS predictions work properly only for the same or very similar kind of "product" (CAMO Software 2017). We assume that, as the decomposed litterbag material differed significantly in their spectral composition after 6,12, and 24 months in the field (Fig. A3 and A4), also their litter traits differed too much to be classified as similar "product". However, we believe that measuring material at each decomposition stage and use that data for building corresponding PLS models would result in highly accurate predictions, as we could already prove for the total $\mathrm{C}$ and $\mathrm{N}$ contents.

Thus, NIRS offers a powerful tool in soil ecology and in decomposition studies (Albrecht et al. 2008). According to our experiences with NIRS and the PLS predictions of alpine litter traits along the decomposition process of 24 months, we advise everyone to collect and estimate generously the needed initial freshly fallen litter material and to be aware that both the litterbag approach and the NIRS measurements need a sufficient amount of litter material left at the end of the decomposition experiments (at least $20 \mathrm{~g}$ air-dried mass).

\section{Leaf litter traits}

For freshly fallen litter material, we found four out of the six alpine plant species to be significantly different in their litter traits and therefore well separable (Fig. 2). Our results are in line with the study of Rief et al. (2012),

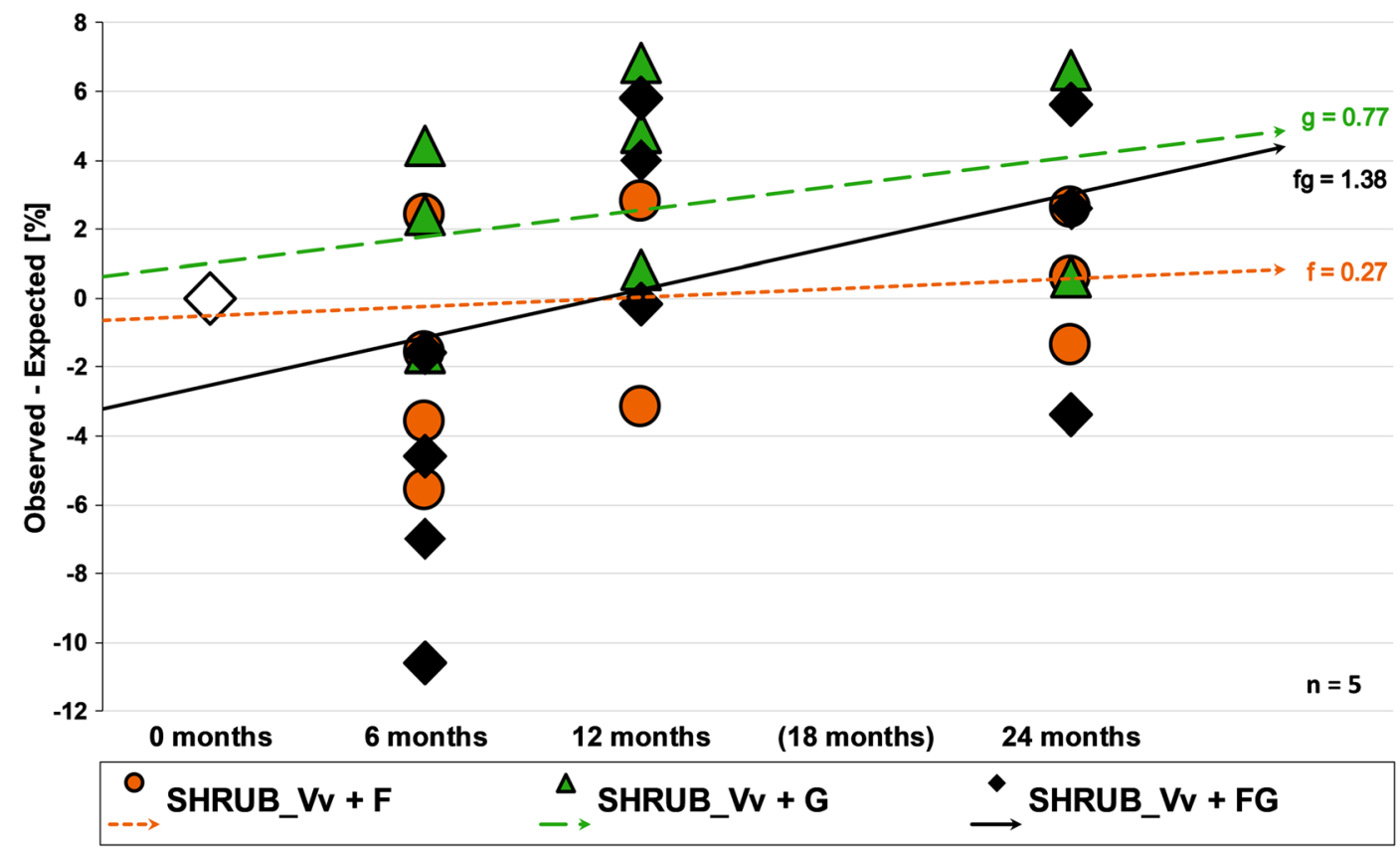

Fig. 3 Non-additive effects of alpine Vaccinium vitis-idaea (SHRUB_Vv) litter material from litter mixtures along a decomposition process. Values were calculated as the deviation of the mean litter mass moss (LML) from the single-species treatments on each sampling date. Positive values indicate synergetic and negative values antagonistic effects. $F$ and $G$ represent the influencing litter type(s) present in the litterbags. Dots represent the single replicates and the variability of each treatment within each time point; the mean values were used to add trend lines and their steepness (i.e. slope) for extrapolations 
which was conducted at the same study site and compared the palatability of eight alpine plant species to invertebrate decomposers; five of them were also used in our study. Regarding decomposability, the plant components can be divided into three groups: rapidly degrading carbohydrates and proteins (the latter expressed here as $\mathrm{N}$ ), slower degrading structural components such as cellulose and hemicellulose (ADF), and recalcitrant lignin and polyphenols (ADL) (Berg and Laskowski 2005).

The three litterbag species, each belonging to a different functional groups, differed significantly in their initial chemical traits (Fig. 2). The evergreen dwarf shrub V. vitis-idaea (i.e. SHRUB_Vv) can be found mainly in abandoned pastures at the study site (Steinwandter et al. 2017) along with other Vaccinium species; it is wide-spread in natural alpine heathland of Eurasia (Meusel et al. 1978) and North America (Flora of North America Editorial Committee 2009). The freshly fallen SHRUB_Vv litter was characterised by the highest lignin content (i.e. ADL), which was also reflected by a high total $\mathrm{C}$ content that exceeded $50 \%$ of their total litter biomass; on average, lignin is composed of $65 \%$ of carbon (Montané et al. 2010). Additionally, freshly fallen litter of Vaccinium spp. and other dwarf shrubs was reported to contain higher amounts of secondary metabolites such as phenols and tannins compared with grass and forb species (Montané et al. 2010; Berg and McClaugherty 2014), thus being responsible for low palatability to large decomposers such as earthworms (Rief et al. 2012). These recalcitrant compounds impair the establishment and growth of microorganisms by forming resistant complexes with proteins and nitrogen (Hättenschwiler and Vitousek 2000), further inhibiting and regulating decomposition processes. However, Rief et al. (2012) reported that after 12 months in the field, the total phenolic concentration in aged dwarf shrub litter decreased considerably (e.g. approximately 90\%), most likely making aged SHRUB_Vv litter again more attractive to the decomposer community.

We found a relatively low total $\mathrm{N}$ content in freshly fallen litter types, with SHRUB_Vv exceeding that of FORB_Gs but not GRASS_Dg. Generally, a high N concentration was found to boost the decomposition of hemicellulose (i.e. ADF) in the first phase of decomposition, but to hamper that of lignin (i.e. ADL) in the long term, thus leading to lower decomposition rates (Berg 2014). This might be true for the SHRUB_Vv litter material where we found high initial lignin: $\mathrm{N}$, lignin, and $\mathrm{N}$ values (Table 1). Further, as the total $\mathrm{C}$ content of SHRUB_Vv treatments was still high after 12 and 24 months in the field, it might indicate that these litter still contained large concentrations of lignin (Berg 2014). Personal observations confirm this, as tough and recalcitrant Vaccinium spp. leaves of different decomposition stages and ages could be found in the litter layer at our study site (see also Seeber and Seeber 2005). The lignin:N ratio was found to be a good predictor of decomposability in tropical and Mediterranean climates, but not in the temperate region (Aerts 1997). Even though we did not test it, our data may indicate that lignin: $\mathrm{N}$ could be a useful and applicable predictor for the decomposability of alpine litter.

Regarding the $\mathrm{C}: \mathrm{N}$ ratios that can be used as index for palatability and litter quality (Amelung et al. 2018), we obtained relatively high values for all freshly fallen litter types ranging from 30 to almost 50. This would suggest the initial litter material to be generally of lowquality mainly due a relatively low total $\mathrm{N}$ versus a high total C content (Amelung et al. 2018). However, the SHRUB_Vv C:N ratios decreased only slowly along decomposition, therefore becoming only slowly more favourable to the decomposer community. On the other hand, the C:N ratios of perennial GRASS_Dg and FORB_Gs significantly dropped after six month, therefore becoming more favourable to decomposers already in the early stages.

\section{Decomposition rates}

The speed and rates of decomposition for SHRUB_Vv, GRASS_Dg, and FORB_Gs were in line with our expectations and the literature (Montané et al. 2010; Duan et al. 2013; Berg 2014). All the litter material degraded rapidly in the beginning followed by gradually decelerating decomposition. SHRUB_Vv as an evergreen plant showed the lowest decomposition rate, while the perennials GRASS_Dg and FORB_Gs degraded significantly faster. Compared with studies from the lowland, we observed lower decomposition rates most probably due to the harsher environmental conditions at our Alpine study site (Gavazov 2010). Generally, decomposition rates highly depend on climate (i.e. temperature and (soil) moisture), the composition of the litter material (i.e. nutritional quality and physical toughness), sitespecific local factors, and the decomposer community (Cornelissen and Thompson 1997; Berg and 
McClaugherty 2014). A fast decomposition can be observed when both temperature and moisture are high, as found in the tropics (Aerts 1997; Bradford et al. 2016). However, cold climates - for example high-elevation and high-latitude environments - only partly fulfil these criteria, as they are characterised by high amounts of precipitation but low temperatures. Additionally, snow can persist for a long period and can return in summer months (Körner 2003). In these cold biomes, temperature, when not limited by soil moisture (Aerts 2006), was found to be the main driver of decomposition rates (Gavazov 2010; Bradford et al. 2016) along with other factors such as the decomposer community composition (Gessner et al. 2010; Kitz et al. 2015). As larger decomposers were excluded in this study, the observed decomposition rates can be accounted solely to the leaf-litter associated microbiome (Knapp et al. 2011).

Interestingly, litter decomposition was found to be quite high and active under the snow cover (Sjögersten and Wookey 2004; Baptist et al. 2010), due to the insulation of the snow pack that keep temperatures close to the freezing point. We recorded decomposition rates up to $42 \%$ LML after the first six months (Table 2) when the litterbags were covered by a $30 \mathrm{~cm}$ thick snow cover for most of the time, which is in line with the literature (Saccone et al. 2013).

\section{Non-additive effects}

Non-additive effects are defined as effects that are greater or less than the sum of two or more net (i.e. additive) effects (Hättenschwiler et al. 2005), the former being called synergistic and the latter antagonistic. We observed both non-additive effects, depending on the functional groups present, with an inconsistent pattern at the beginning of the decomposition processes and a synergistic trend after six months. This is consistent with Duan et al. (2013) who studied litter mixtures of up to 25 species in alpine meadows on the Tibetan Plateau and found antagonistic as well as synergistic effects in few-species mixtures, especially when shrubs were included. However, with an increasing number of litter types mixed with shrubs, mostly synergistic effects were recorded. In our study, GRASS_Dg showed the highest synergistic effects of all treatments followed by the SHRUB_Vv, hinting that adding at least one other functional litter type already increases the overall decomposition rate considerably (Fig. 2). The effect was even more pronounced for SHRUB_Vv and
GRASS_Dg in the 3-species mixtures with a highly significant effect for GRASS_Dg + SF. Cuchietti et al. (2014) reported that high-quality litter can stimulate the decomposition of low-quality litter and vice-versa, hence benefit the decomposability of all interacting litter types. Our results for SHRUB_Vv and GRASS_Dg in mixtures fit into this scheme as both litter types significantly accelerated each other's decomposition (i.e. SHRUB_Vv + G, GRASS_Dg + S, and GRASS_Dg + $\mathrm{SF}$ ). The reason might be a nutrient transfer from the high to the low-quality litter, leading to an elevated attraction of the species-specific microbiome (Hättenschwiler et al. 2005). Rief et al. (2012) found well separable communities of microorganisms inhabiting litter of eight alpine plant species from the same study site, which also included five species investigated from our study. A different picture was found for FORB_Gs, for which only adding SHRUB_Vv slightly increased decomposition (Table 2 and Fig. S6). In fact, we assume that in the first phase of decomposition GRASS_Dg and FORB_Gs negatively influence each other, the latter hampering decomposition in mixtures more severely. However, FORB_Gs had the highest mean decomposition rate of all tested litter types, therefore adding one or two litter types might slow down the decomposition processes due to a deficit of $\mathrm{N}$ and/or $\mathrm{P}$ (Zheng et al. 2017).

The finding that alpine low-quality dwarf shrub litter decomposition is accelerated when present in mixtures with high-quality litter types is of actual interest regarding ongoing land-use changes in Alpine pasturelands (Schirpke et al. 2013). These were shaped by extensive low-input agriculture for centuries, but are increasingly taken out of management due to socio-economic reasons (MacDonald et al. 2000), although being of high conservation status in the Habitats Directive (European Commission 1992). In sub-alpine pastureland, abandonment is followed by dwarf shrub encroachment, aggravated by global warming (Brigham et al. 2018), leading to high amounts of litter accumulation (Seeber and Seeber 2005; Steinwandter et al. 2017) and slow rates of decomposition (Montané et al. 2010), with mostly negative effects on various ecosystem services. However, these effects could be partly mitigated by the observed synergistic effects when low-quality litter occurs in mixtures with high-quality litter and by generally higher net-decomposition rates induced by global warming (Cornelissen et al. 2007; Luo et al. 2010; Duan et al. 2013). 
Acknowledgments We thank the Pfurtscheller family for giving field permission to sample the study sites and for information about the management regime. We thank the association "Verein zur Förderung der wissenschaftlichen Ausbildung und Tätigkeit von Südtirolern an der Landesuniversität Innsbruck" for providing a research scholarship for Michael Steinwandter. We thank Nikolaus Obojes for critically commenting on the manuscript. We thank Georg Leitinger and Mario Deutschmann for providing climate data from the study site, as well as Aldo Matteazzi from the fodder analysis laboratory at Laimburg Research Centre in Auer/Ora, Italy and Gry Larsen from University of Innsbruck, Austria for conducting the litter trait measurements. We further thank the anonymous reviewers for their most valuable comments and the editor for editing efforts.

Funding Information Open access funding provided by University of Innsbruck and Medical University of Innsbruck.

Open Access This article is distributed under the terms of the Creative Commons Attribution 4.0 International License (http:// creativecommons.org/licenses/by/4.0/), which permits unrestricted use, distribution, and reproduction in any medium, provided you give appropriate credit to the original author(s) and the source, provide a link to the Creative Commons license, and indicate if changes were made.

\section{References}

Aerts R (1997) Climate, leaf litter chemistry and leaf litter decomposition in terrestrial ecosystems: a triangular relationship. Oikos 79:439. https://doi.org/10.2307/3546886

Aerts R (2006) The freezer defrosting: global warming and litter decomposition rates in cold biomes. J Ecol 94:713-724. https://doi.org/10.1111/j.1365-2745.2006.01142.x

Aerts R, Chapin FS (1999) The mineral nutrition of wild plants revisited: a re-evaluation of processes and patterns. In: advances in ecological research, 1st edn. pp $1-67$

Agelet LE, Hurburgh CR (2010) A tutorial on near infrared spectroscopy and its calibration. Crit Rev Anal Chem 40: 246-260. https://doi.org/10.1080/10408347.2010.515468

Albrecht R, Joffre R, Gros R, le Petit J, Terrom G, Périssol C (2008) Efficiency of near-infrared reflectance spectroscopy to assess and predict the stage of transformation of organic matter in the composting process. Bioresour Technol 99: 448-455. https://doi.org/10.1016/j.biortech.2006.12.019

Amelung W, Blume H-P, Fleige H, et al (2018) Scheffer/ Schachtschabel Lehrbuch der Bodenkunde, 17th edn. Springer Spektrum, Heidelberg, Germany

Baptist F, Yoccoz NG, Choler P (2010) Direct and indirect control by snow cover over decomposition in alpine tundra along a snowmelt gradient. Plant Soil 328:397-410. https://doi. org/10.1007/s11104-009-0119-6

Bates D, Mächler M, Bolker B, Walker S (2014) Fitting linear mixed-effects models using lme4. J Stat Softw 67:1-51. https://doi.org/10.18637/jss.v067.i01

Berg B (2014) Decomposition patterns for foliar litter - a theory for influencing factors. Soil Biol Biochem 78:222-232. https://doi.org/10.1016/j.soilbio.2014.08.005
Berg B, Laskowski R (2005) Litter decomposition: a guide to carbon and nutrient turnover. In: Academic press. United Kingdom, London

Berg B, McClaugherty C (2014) Plant Litter, 3rd edn. Springer, Heidelberg, Germany

Bradford MA, Berg B, Maynard DS, Wieder WR, Wood SA (2016) Understanding the dominant controls on litter decomposition. J Ecol 104:229-238. https://doi.org/10.1111/13652745.12507

Brigham LM, Esch EH, Kopp CW, Cleland EE (2018) Warming and shrub encroachment decrease decomposition in arid alpine and subalpine ecosystems. Arct Antarct Alp Res 50: e1494941. https://doi.org/10.1080/15230430.2018.1494941

CAMO Software (2017) The Unscrambler User Manual - The Unscrambler X 10.5

Chang C-W, Laird DA, Mausbach MJ, Hurburgh CR (2001) Nearinfrared reflectance spectroscopy-principal components regression analyses of soil properties. Soil Sci Soc Am J 65: 480. https://doi.org/10.2136/sssaj2001.652480x

Chen Y, Sun J, Xie F, Wang X, Cheng G, Lu X (2015) Litter chemical structure is more important than species richness in affecting soil carbon and nitrogen dynamics including gas emissions from an alpine soil. Biol Fertil Soils 51:791-800. https://doi.org/10.1007/s00374-015-1025-0

Chodak M (2008) Application of near infrared spectroscopy for analysis of soils, litter and plant materials. Polish J EnvironStud 17:631-642

Cornelissen JHC, Thompson K (1997) Functional leaf attributes predict litter decomposition rate in herbaceous plants. New Phytol 135:109-114. https://doi.org/10.1046/j.14698137.1997.00628.x

Cornelissen JHC, Van Bodegom PM, Aerts R et al (2007) Global negative vegetation feedback to climate warming responses of leaf litter decomposition rates in cold biomes. Ecol Lett 10: 619-627. https://doi.org/10.1111/j.1461-0248.2007.01051.x

Coûteaux MM, Bottner P, Berg B et al (1995) Litter decomposition, climate and litter quality. Trends Ecol Evol 10:63-66. https://doi.org/10.1016/S0169-5347(00)88978-8

Cuchietti A, Marcotti E, Gurvich DE, Cingolani AM, Pérez Harguindeguy N (2014) Leaf litter mixtures and neighbour effects: low-nitrogen and high-lignin species increase decomposition rate of high-nitrogen and low-lignin neighbours. Appl Soil Ecol 82:44-51. https://doi.org/10.1016/j. apsoil.2014.05.004

Duan J, Wang S, Zhang Z, Xu G, Luo C, Chang X, Zhu X, Cui S, Zhao X, Wang W, du M (2013) Non-additive effect of species diversity and temperature sensitivity of mixed litter decomposition in the alpine meadow on Tibetan plateau. Soil Biol Biochem 57:841-847. https://doi.org/10.1016/j. soilbio.2012.08.009

European Commission (1992) Council directive 92/43/EEC of 21 May 1992 on the conservation of natural habitats and of wild fauna and flora. Off J Eur Communities 206:7-50. 2004R0726 - v.7 of 05.06.2013

Flora of North America Editorial Committee (2009) Flora of North America, Volume 8, Magnoliophyta: Paeoniaceae to Ericaceae. Oxford University Press, New York, New York

Foley WJ, McIlwee A, Lawler I, Aragones L, Woolnough AP, Berding N (1998) Ecological applications of near infrared reflectance spectroscopy - a tool for rapid, cost-effective prediction of the composition of plant and animal tissues 
and aspects of animal performance. Oecologia 116:293-305. https://doi.org/10.1007/s004420050591

Gartner TB, Cardon ZG (2004) Decomposition dynamics in mixed-species leaf litter. Oikos 104:230-246. https://doi. org/10.1111/j.0030-1299.2004.12738.x

Gavazov KS (2010) Dynamics of alpine plant litter decomposition in a changing climate. Plant Soil 337:19-32. https://doi. org/10.1007/s11104-010-0477-0

Gessner MO, Swan CM, Dang CK, McKie BG, Bardgett RD, Wall DH, Hättenschwiler S (2010) Diversity meets decomposition. Trends Ecol Evol 25:372-380. https://doi. org/10.1016/j.tree.2010.01.010

Hättenschwiler S, Vitousek PM (2000) The role of polyphenols in terrestrial ecoystems nutrient cycling. Tree 15:238-243. https://doi.org/10.1016/S0169-5347(00)01861-9

Hättenschwiler S, Tiunov AV, Scheu S (2005) Biodiversity and litter decomposition in terrestrial ecosystems. Annu Rev Ecol Evol Syst 36:191-218. https://doi.org/10.1146/annurev. ecolsys.36.112904.151932

Ingrisch J, Karlowsky S, Anadon-Rosell A, Hasibeder R, König A, Augusti A, Gleixner G, Bahn M (2017) Land use alters the drought responses of productivity and $\mathrm{CO} 2$ fluxes in mountain grassland. Ecosystems 21:1-15. https://doi.org/10.1007 /s10021-017-0178-0

IPCC (2013) Climate Change 2013: The physical science basis. Contribution of working Group I to the fifth assessment report of the intergovernmental panel on climate change. Cambridge University Press, Cambridge, United Kingdom

Joffre R, Gillon D, Dardenne P, Agneessens R, Biston R (1992) The use of near-infrared reflectance spectroscopy in litter decomposition studies. Ann des Sci For 49:481-488

Kinzner M-C, Wagner HC, Peskoller A, Moder K, Dowell FE, Arthofer W, Schlick-Steiner BC, Steiner FM (2015) A nearinfrared spectroscopy routine for unambiguous identification of cryptic ant species. PeerJ 3:e991. https://doi.org/10.7717 /peerj.991

Kitz F, Steinwandter M, Traugott M, Seeber J (2015) Increased decomposer diversity accelerates and potentially stabilises litter decomposition. Soil Biol Biochem 83:138-141. https://doi.org/10.1016/j.soilbio.2015.01.026

Knapp BA, Rief A, Seeber J (2011) Microbial communities on litter of managed and abandoned alpine pastureland. Biol Fertil Soils 47:845-851. https://doi.org/10.1007/s00374011-0561-5

Körner C (2003) Alpine Plant Life. In: Springer Berlin Heidelberg. Berlin, Germany

Liu Y, Chen Y, Zhang J, Yang W, Peng Z, He X, Deng C, He R (2016) Changes in foliar litter decomposition of woody plants with elevation across an alpine forest-tundra ecotone in eastern Tibet plateau. Plant Ecol 217:495-504. https://doi. org/10.1007/s11258-016-0594-9

Luo C, Xu G, Chao Z et al (2010) Effect of warming and grazing on litter mass loss and temperature sensitivity of litter and dung mass loss on the Tibetan plateau. Glob Chang Biol 16: 1606-1617. https://doi.org/10.1111/j.13652486.2009.02026.x

MacDonald D, Crabtree JR, Wiesinger G, Dax T, Stamou N, Fleury P, Gutierrez Lazpita J, Gibon A (2000) Agricultural abandonment in mountain areas of Europe: environmental consequences and policy response. J Environ Manag 59:4769. https://doi.org/10.1006/jema.1999.0335
Martinez IG, Zagal EV, Ovalle CM et al (2010) Litter decomposition of Acacia caven (Molina) Molina and Lolium multiflorum Lam. in mediterranean climate ecosystems. Chil J Agric Res 70:454-464. https://doi.org/10.4067 /S0718-58392010000300013

Meusel H, Jager E, Rauschert S, Weinert E (1978) Vergleichende Chorologie der Zentraleuropaischen Flora, Band II. Fischer Verlag, Jena, Germany

Montané F, Romanyà J, Rovira $\mathrm{P}$, Casals $\mathrm{P}$ (2010) Aboveground litter quality changes may drive soil organic carbon increase after shrub encroachment into mountain grasslands. Plant Soil 337:151-165. https://doi.org/10.1007/s11104-0100512-1

Olson JS (1963) Energy storage and the balance of producers and decomposers in ecological systems. Ecology 44:322-331. https://doi.org/10.2307/1932179

Parsons SA, Lawler IR, Congdon RA, Williams SE (2011) Rainforest litter quality and chemical controls on leaf decomposition with near-infrared spectrometry. J Plant Nutr Soil Sci 174:710-720. https://doi.org/10.1002/jpln.201100093

Pruchniewicz D (2017) Abandonment of traditionally managed Mesic mountain meadows affects plant species composition and diversity. Basic Appl Ecol 20:10-18. https://doi. org/10.1016/j.baae.2017.01.006

R Core Team (2018) R: A language and environment for statistical computing. R Foundation for Statistical Computing, Vienna, Austria

Reich G (2005) Near-infrared spectroscopy and imaging : basic principles and pharmaceutical applications. Adv Drug Deliv Rev 57:1109-1143. https://doi.org/10.1016/j. addr.2005.01.020

Rief A, Knapp BA, Seeber J (2012) Palatability of selected alpine plant litters for the decomposer Lumbricus rubellus (Lumbricidae). PLoS One 7. https://doi.org/10.1371/journal. pone. 0045345

RStudio Team (2016) RStudio: Integrated Development for R. RStudio, Inc., Boston, Massachusetts

Saccone P, Morin S, Baptist F, Bonneville JM, Colace MP, Domine F, Faure M, Geremia R, Lochet J, Poly F, Lavorel S, Clément JC (2013) The effects of snowpack properties and plant strategies on litter decomposition during winter in subalpine meadows. Plant Soil 363:215-229. https://doi. org/10.1007/s11104-012-1307-3

Schirpke U, Leitinger G, Tasser E, Schermer M, Steinbacher M, Tappeiner U (2013) Multiple ecosystem services of a changing alpine landscape: past, present and future. Int J Biodivers Sci Ecosyst Serv Manag 9:123-135. https://doi.org/10.1080 /21513732.2012.751936

Seeber J, Seeber GUH (2005) Effects of land-use changes on humus forms on alpine pastureland (Central Alps, Tyrol). Geoderma 124:215-222. https://doi.org/10.1016/j. geoderma.2004.05.002

Sjögersten S, Wookey PA (2004) Decomposition of mountain birch leaf litter at the forest-tundra ecotone in the Fennoscandian mountains in relation to climate and soil conditions. Plant Soil 262:215-227. https://doi.org/10.1023 /B:PLSO.0000037044.63113.fe

Steinwandter M, Schlick-Steiner BC, Seeber GUH, Steiner FM, Seeber J (2017) Effects of alpine land-use changes: soil macrofauna community revisited. Ecol Evol 7:5389-5399. https://doi.org/10.1002/ece3.3043 
Ter Braak, CJF, Šmilauer P (2018) Canoco reference manual and user's guide: software for ordination, version 5.10. Microcomputer Power, Ithaca, New York

VDLUFA (2018) Methodenbuch. Band III, Die chemische Untersuchung von Futtermitteln. VDLUFA - Verlag, Darmstadt, Germany

Wang S, Ruan H, Han Y (2010) Effects of microclimate, litter type, and mesh size on leaf litter decomposition along an elevation gradient in the Wuyi Mountains, China. Ecol Res 25:1113-1120. https://doi.org/10.1007/s11284-010-0736-9

Xu GP, Hu YG, Wang SP, Zhang Z, Chang X, Duan J, Luo C, Chao Z, Su A, Lin Q, Li Y, du M (2010) Effects of litter quality and climate change along an elevation gradient on litter mass loss in an alpine meadow ecosystem on the Tibetan plateau. Plant Ecol 209:257-268. https://doi.org/10.1007/s11258-009-9714-0
Zangerlé A, Hissler C, Blouin M, Lavelle P (2014) Near infrared spectroscopy (NIRS) to estimate earthworm cast age. Soil Biol Biochem 70:47-53. https://doi.org/10.1016/j. soilbio.2013.11.023

Zheng Z, Mamuti M, Liu H, Shu Y, Hu S, Wang X, Li B, Lin L, Li X (2017) Effects of nutrient additions on litter decomposition regulated by phosphorus-induced changes in litter chemistry in a subtropical forest, China. For Ecol Manag 400:123-128. https://doi.org/10.1016/j. foreco.2017.06.002

Publisher's note Springer Nature remains neutral with regard to jurisdictional claims in published maps and institutional affiliations. 